\title{
Casting a Wider Net on Ocean NETs
}

\author{
Emily Cox ${ }^{1 *}$, Miranda Boettcher ${ }^{2,3}$, Elspeth Spence ${ }^{1}$ and Rob Bellamy ${ }^{4}$ \\ ${ }^{1}$ School of Psychology, Cardiff University, Cardiff, United Kingdom, ${ }^{2}$ Copernicus Institute of Sustainable Development, \\ Utrecht University, Utrecht, Netherlands, ${ }^{3}$ Institute for Advanced Sustainability Studies (IASS), Potsdam, Germany, \\ ${ }^{4}$ Department of Geography, The University of Manchester, Manchester, United Kingdom
}

\section{OPEN ACCESS}

Edited by:

Lennart Thomas Bach

University of Tasmania, Australia

Reviewed by:

Phillip Williamson,

University of East Anglia,

United Kingdom

Jonathan Symons,

Macquarie University, Australia

*Correspondence:

Emily Cox

CoxE3@cardiff.ac.uk

Specialty section:

This article was submitted to

Negative Emission Technologies,

a section of the journal

Frontiers in Climate

Received: 25 June 2020 Accepted: 07 January 2021

Published: 02 February 2021

Citation:

Cox E, Boettcher M, Spence E and Bellamy R (2021) Casting a Wider Net on Ocean NETS.

Front. Clim. 3:576294.

doi: 10.3389/fclim.2021.576294
Societal issues involving policies and publics are generally understudied in research on ocean-based Negative Emission Technologies (NETs), yet will be crucial if novel techniques are ever to function at scale. Public attitudes are vital for emerging technologies: publics influence political mandates, help determine the degree of uptake by market actors, and are key to realizing broader ambitions for robust decision-making and responsible incentivization. Discourses surrounding ocean NETs will also have fundamental effects on how governance for the techniques emerges, shaping how they are defined as an object of governance, who is assigned the authority to govern, and what instruments are deemed appropriate. This Perspective brings together key insights on the societal dimensions of ocean NETs, drawing on existing work on public acceptability, policy assessment, governance, and discourse. Ocean iron fertilization is the only ocean NET on which there exists considerable social science research thus far, and we show that much evidence points against its social desirability. Taken in conjunction with considerable natural science uncertainties, this leads us to question whether further research is actually necessary in order to rule out ocean iron fertilization as an option. For other ocean NETs, there is a need for further research into social dimensions, yet research on analogous technologies shows that ocean interventions will likely evoke strong risk perceptions, and evidence suggests that the majority of ocean NETs may face a greater public acceptability challenge than terrestrial NETs. Ocean NETs also raise complex challenges around governance, which pose questions well-beyond the remit of the natural sciences and engineering. Using a conceptual exploration of the ways in which different types of discourse may shape emerging ocean NETs governance, we show that the very idea of ocean NETs is likely to set the stage for a whole new range of contested futures.

Keywords: carbon dioxide removal, public perceptions, governance, policy assessment, discourse, negative emissions, climate change, marine geoengineering

\section{INTRODUCTION}

Given current atmospheric concentrations of greenhouse gases, it seems increasingly likely that both unprecedented emissions reductions and gigatonne-scale $\mathrm{CO}_{2}$ removal will be required to keep global average temperature increase to "well below $2^{\circ} \mathrm{C}$ " (National Academies of Sciences, 2019). NET proposals are heterogeneous, with large uncertainties around their risks and benefits. As a hedge against unforeseen risks, including the risk of technology failure, some technical experts advise that it would be wise to explore a diverse range of NETs alongside ambitious efforts to reduce emissions (Lomax et al., 2015; Nemet et al., 2018). 
The ocean has been posited by some as suitable for NETs because of its large available area, and the potential for $\mathrm{CO}_{2}$ sequestration over extremely long timescales; yet the idea of intervening in complex marine ecosystems poses significant risks and societal concerns (GESAMP, 2019). Therefore, more research will be needed to assess which ocean NETs, where, at what scale, and under what societal conditions, might be considered as part of the climate response "toolbox." A wide variety of ocean NETs have been proposed, operating at different scales, including proposals for coastal waters (for example, restoring sea grasses and mangrove ecosystems), and proposals for international waters and the deep ocean (for example, ocean iron fertilization, direct injection of $\mathrm{CO}_{2}$, or ocean upwelling/downwelling), as well as proposals ranging from utilization of existing biological systems to the development of highly novel engineering technologies. The technological characteristics of various ocean NETs proposals have been explored in more detail within the literature than the social science aspects; see GESAMP (2019) and National Academies of Sciences (2019) for an overview.

In this Perspective, we emphasize that assessments of the potential of ocean NETs must not be limited to technical, physical and economic questions. Research on negative emissions tends to focus on "supply-side" topics such as sequestration potential, resource availability, and cost (Nemet et al., 2018). Yet the demand side, including publics, policies and governance, will be just as important for assessing the "real world" potential of ocean NETs. Engaging with social science questions early on may help to anticipate potential pitfalls in technology development and inform the design of responsible governance mechanisms to avoid them. Engaging with wider society can additionally help to identify broader issues which experts might have missed, because they come into the topic "without blinkers on" (Cox et al., 2020a). It is also vital to assess policy options early in the innovation process, because most new technologies require the development of novel policy frameworks. Understanding the social science of ocean NETs also requires looking not only at the technologies and policies themselves, but also at the ways in which we talk about them. Understanding how discourses shape technology governance can help to avoid premature closure around solutions which may appear optimal according to particular types of knowledge, whilst simultaneously crowding out other options. This Perspective explores three fundamental aspects of the social science of ocean NETs: public perceptions, policy assessment, and the role of discourse in technology governance. The first three sections address these topics in turn, drawing on existing work on ocean NETs as well as analogous and related technologies and systems. We then identify common threads across these diverse bodies of literature, concluding with insights into the roles social science can play in the ethical and effective assessment of ocean NETs' potential as a climate response strategy.

\section{PUBLIC PERCEPTIONS}

There is little existing empirical work on public perceptions of ocean NETs. However, we can develop an idea of how perceptions are likely to emerge from research on public perceptions of the ocean, terrestrial NETs, and climate engineering (CE). Certain risk attributes have been shown to be important for a diverse range of technologies: these include the degree of control people have over the risk, its voluntariness, the possible severity of consequences, and the familiarity of the risk or system (Fischhoff et al., 1978; Slovic, 1987). In this respect, many ocean NETs proposals may be perceived as highly risky in the same way as nuclear power or Solar Radiation Management. One early UK study found lower support for ocean liming and ocean iron fertilization than for atmospheric sulfate injection, because of concerns about the riskiness, unpredictability and uncontrollability of the ocean environment (Ipsos Mori, 2010).

Previous work suggests that research carried out at small scale and under well-controlled conditions is likely to be generally acceptable (Cummings et al., 2017). However, in this respect the ocean presents challenges similar to atmospheric $\mathrm{CE}$, because people may be skeptical of scientists' abilities to carry out controlled and accurate research in such an open, interconnected system (Pidgeon et al., 2013). A crucial determinant will be the extent to which ocean NETs are perceived to "tamper with nature" (Corner et al., 2013; Wolske et al., 2019). For example, when discussing oceanic disposal of $\mathrm{CO}_{2}$, people in the United States expressed concerns about the impact this would have on marine organisms and saw it as "...messing with some form of life..." (Palmgren et al., 2004). The ocean is often perceived as fragile and pristine (Hawkins et al., 2016; Cox et al., 2020b), and research finds that ocean NETs might be seen as overstepping the limits of human ability to understand and control the environment (Macnaghten et al., 2015; Wibeck et al., 2017; Gannon and Hulme, 2018). Research in Scotland and Norway found that people felt changes in the deep sea would personally impact them and they were not confident in the abilities of management to protect the marine environment (Ankamah-Yeboah et al., 2020). The concern people express about the ocean is commonly linked to a positive emotional connection with it (McMahan and Estes, 2015), shown to be important for perceptions of ocean acidification (Spence et al., 2018). Despite low levels of prior awareness of ocean acidification, research in the US and UK demonstrates consistently high levels of public concern and strong emotional feelings (Capstick et al., 2016; Cooke and Kim, 2019). Importantly, NETs research suggests that emotional connection to the ocean manifests similarly in coastal and inland populations (Cox et al., 2020b).

That said, some ocean-based techniques may be perceived as more "natural" than others, for example restoration of coastal ecosystems such as mangroves, salt marshes or sea grass habitats which act as carbon sinks. Destruction of coastal ecosystems currently means that much of the carbon storage potential of these areas is being lost (Luisetti et al., 2019), and reversal of this could be perceived as a restoration of nature, rather than tampering. Similar terrestrial techniques such as peatland restoration are generally assumed to be unproblematic in terms of public perceptions (Royal Society and Royal Academy of Engineering, 2018), and work on terrestrial afforestation demonstrates that it is generally preferred (Wolske et al., 2019). However, perceptions of what constitutes 
"natural" are fuzzy, dynamic, and contested, partly because even "pristine" landscapes are often the product of enormous human intervention (Corner et al., 2013). The specific context will be important: coastal restoration projects are not always without conflict, and can be socially or environmentally problematic (Myatt et al., 2003; Srivastava and Mehta, 2017). Work on terrestrial NETs also suggests that there may be trade-offs between the social and ethical impacts of a technique, and its scale of operation, which in turn affects its $\mathrm{CO}_{2}$ sequestration potential (Cox et al., 2018); habitat restoration techniques may not benefit from the space afforded by transnational waters, and may be fundamentally constrained in their ability to sequester $\mathrm{CO}_{2}$ over long timeframes (National Academies of Sciences, 2019).

Importantly, support or opposition for a particular project or research trial cannot be easily predicted, because it depends on when, where, and how it is implemented (Gough and Mander, 2019). Perceptions are neither fixed nor immutable, particularly in the early stages of technology scale-up; meaningful public engagement, drawing on lessons learned from other technologies, will be crucial (cf. Lockwood, 2017; Williams et al., 2017; Dwyer and Bidwell, 2019). Such flexibility early on means that views can be influenced by those with a platform, including the media, environmental organizations, and influential individuals such as celebrities or scientific advocates. For example, the first ocean iron fertilization projects encountered strong opposition from environmental organizations, which echoed people's feelings about the fragility, uncontrollability and inherent preciousness of the ocean (Fuentes-George, 2017). Such opposition was an important factor in the development of highly influential governance mechanisms which forbid the dumping of materials at sea (IMO, 2020). For lay publics, however, knowledge about novel ocean technologies is likely to be extremely low, meaning that at this stage perceptions may be mainly influenced by emotion and by risk attributes which cut across technology types (Macnaghten et al., 2015; Spence et al., 2018).

Views will also be constructed through contextually-specific local meanings (Mabon et al., 2014; Gannon and Hulme, 2018), and cultural differences will be important, such as the extent to which the ocean is perceived as an important food provider (Potts et al., 2016). Acceptance will also be highly conditional: for example, NETs are more likely to be supported as part of a package of emissions reduction policies, thus reassuring people that the "root cause" of climate change is being tackled (Cox et al., 2020b). Carbon capture and storage is widely seen as a "non-transition" (Butler et al., 2013; Mabon and Shackley, 2015), and any perception that ocean NETs are being used to continue business-as-usual may be damaging. Thus, rather than asking whether ocean NETs are publicly "acceptable," it is more useful to identify the conditions under which a proposal might be perceived as reasonable by many people (Cox et al., 2018). Western and developing nations may also differ (Pidgeon et al., 2013; Carr and Yung, 2018), and in this respect we have precious little understanding of risk perceptions in non-western contexts. For example, a 2017 review of public perceptions research on climate engineering identified 23 studies, of which 19 included Western Europeans samples, 5 US/Canadian, and only one included a non-OECD nation. In more recent years, research on public perceptions has increased, yet the historical imbalance remains. A small number of studies find that risk perceptions in non-Western and non-affluent areas include several similar concerns regarding scale, unintended consequences, and irreversibility of techniques taking place in open environments (Winickoff et al., 2015; Carr and Yung, 2018). A study of Global South stakeholders on climate engineering found that even small experiments in open environments encountered concern regarding both physical and social risks (Winickoff et al., 2015).

\section{POLICY ASSESSMENT}

Publics-in combination with diverse experts and stakeholdersare also key to realizing broader ambitions for robust decisionmaking on ocean NETs. The early stage of technology development makes assessments particularly sensitive to framing effects, i.e., the conditioning of outcomes from the ways in which assessors choose to organize and communicate their assessments. Early assessments of ocean NETs have been criticized for adopting narrow framings that, among other things, employ reductive methods, exclude diverse forms of expertise, marginalize alternative options, disregard social criteria, and downplay uncertainties (Bellamy et al., 2012). Such framings have made certain technologies appear to be optimal courses of action; yet they only appear optimal under the narrow set of framings upon which their ostensible optimality is based. Accordingly, efforts are underway to broaden out and open up the framings going into assessments of ocean NETs, and to thereby render decision-making more robust. Such methods involve diverse participants, include alternative options, factor in social criteria, and are candid about uncertainties. The full range of ocean NETs are yet to be given this treatment; initial assessments of attitudes to ocean iron fertilization in Europe and Japan show it to be among the options for tackling climate change with the lowest level of public support (Bellamy et al., 2013, 2017; Amelung and Funke, 2015; Asayama et al., 2017; Jobin and Siegrist, 2020), but open policy assessment must also recognize the variety of ocean techniques, and as shown above, some may not experience the same issues as ocean iron fertilization.

These kinds of assessment are also key to growing calls for the responsible incentivization of research (Bellamy, 2018). Research into ocean NETs is undoubtedly needed, but this must be done responsibly, through broad societal participation in choosing which, if any, ocean NETs to incentivize in the first place, and continued participation in how to incentivize those NETs and ultimately in how to govern them. Building on cognate concepts of responsible innovation (Owen et al., 2013) and development (Waller et al., 2020), such a framework for incentivization encourages policy institutions and actors to go beyond technical considerations of policy design that would treat ocean NETs as though they were already fixed technologies or approaches. Instead, they are encouraged to engage with the diverse geographies of knowledge-making through which the pros and cons of ocean NETs will be negotiated in realworld contexts (Hulme, 2010). In this way, incentive and 
governance regimes are not predefined for society, but defined through societal participation. So far, research is yet to gather social intelligence on what responsibly incentivized ocean NETs might look like. However, work on other NETs shows that incentives have so far been poorly aligned with societal values (Cox and Edwards, 2019) and that policy instrument choice can significantly affect public attitudes toward the technologies themselves (Bellamy et al., 2019).

More is known about preferences for governing ocean NETs. General principles drawn from the public include: (1) transparency of purposes, activities and reporting; (2) minimization and monitoring of environmental impacts; (3) independence from private interests, or at the very least sufficient oversight of them; (4) qualification of scales by perceived controllability; and (5) technology- and activityspecific governance protocols (Bellamy, 2018). Yet the dynamic and multi-faceted nature of public perceptions complicates matters, and experimental research has shown that views on what forms of governance should apply at different stages of research vary amongst people of differing underlying "worldviews" (Bellamy et al., 2017). Some have felt that selfregulation by scientists constitutes sufficient governance for small-scale or "contained" research, whereas others believe that only computational modeling should be left to self-regulation. However, people with various cultural worldviews often feel that international agreements will be necessary for large-scale, outdoors, or "uncontained" research.

\section{THE ROLE OF DISCOURSE}

Environmental and climate governance is shaped by discourse, therefore analyzing debates around emerging technologies can help us to understand how governance "truths" are produced (Leipold et al., 2019). Some work has investigated discourses on terrestrial NETs (Boettcher, 2020; Cox et al., 2020a; Low and Schäfer, 2020), but there has generally been little focus on oceanbased NETs apart from ocean iron fertilization. Most literature focuses on a run of highly controversial iron fertilization experiments between 2001 and 2012 (Buck, 2014; FuentesGeorge, 2017; Horton, 2017; Gannon and Hulme, 2018), and the unique procedural dynamics of these experiments means that caution must be taken when extrapolating to other projects or technologies. However, they do provide useful lessons for other ocean NETs, in that controversy stemmed in part from divergent framings around the value of scientific uncertainty (FuentesGeorge, 2017) and around mankind's relationship with nature (Gannon and Hulme, 2018).

A wider body of research on CE assesses how different types of discourse may be shaping the development of technology governance (Harnisch et al., 2015; Biermann and Möller, 2019; Boettcher, 2019; Low and Boettcher, 2020; Möller, 2020). This research has demonstrated how discussions on the feasibility and responsibility of various $\mathrm{CE}$ approaches have prioritized scientific and technical knowledge types (Matzner and Barben, 2018, 2020; Low and Schäfer, 2020). This is seen as particularly problematic in the Global South, where memories of broken promises mean that NETs may be seen as means for the Global North to avoid their responsibilities to reduce emissions (Cox et al., 2020a; Möller, 2020). Although the heterogeneous range of CE proposals raise differing governance challenges, a bounded range of expert knowledges have been shown to have both direct de facto governance effects on how the various techniques are being researched and developed, and indirect effects on how de jure governance (policy) is emerging (Boettcher, 2019; Gupta and Möller, 2019). Yet analyses have also shown that the idea of intervening into global systems-in particular the oceansraises a plethora of governance questions which lie beyond the scope of purely scientific knowledge (Buck, 2014; Gannon and Hulme, 2018; McLaren, 2018). Given that ocean NETs research is still in its preliminary stages, there may be a greater opportunity to establish knowledge diversity before governance begins to emerge.

One promising analytical framework for exploring the link between discourse and ocean NETs governance is the Sociologyof-Knowledge Approach to Discourse (SKAD) (Keller, 2011; Boettcher, 2019). According to this approach, discourses are underpinning systems of knowledge which shape understandings of why governance is necessary, what is to be governed, by whom, and how. Therefore, discourses have a constitutive effect on what type of governance is "thinkable and practicable to both its practitioners and to those upon whom it is practiced" (Gordon, 1991, p. 3). If different systems of knowledge (discourses) become privileged in ocean NETs governance discussions, they will have varying implications for what types of governance become "thinkable and practicable." To illustrate this, Table 1 contains a set of knowledge types which are present in the current ocean NETs debate, and a conceptual exploration of the different ways they may shape the why, what, who, and how of emerging ocean NETs governance. The table is based on a preliminary review of key literature on ocean NETs (IOC, 2010; Buck, 2014; Horton, 2017; Gannon and Hulme, 2018; Gattuso et al., 2018; Keller, 2018; Brent et al., 2019; GESAMP, 2019; McDonald et al., 2019), using a SKAD-based approach to map underpinning discourse types (see Boettcher, 2019, 2020). This thought experiment is not intended to be exhaustive or conclusive; yet it illustrates the varied, and potentially conflicting, implications that foregrounding legal, biogeochemical, economic, or cultural discourses in ocean NETs governance development may have.

\section{DISCUSSION}

This exploration of existing social science research on ocean NETs has, first and foremost, highlighted how limited the state of knowledge currently is. The only technique that has received a significant degree of attention so far is ocean iron fertilization, which has been roundly condemned in work on public perceptions and policy assessment (at least in OECD contexts), and has raised considerable concerns around prospective governance frameworks. Taken in conjunction with the exceptionally uncertain natural science of ocean iron fertilization (Strong et al., 2015), we might reasonably question whether further research is necessary in order to rule this out as an option.

In the absence of empirical research into the various other proposals for novel ocean NETs, reasonable inferences can be drawn from work on analogous techniques, including terrestrial 
TABLE 1 | Shaping implications of different types of discourse for emerging Ocean NETS governance ${ }^{a}$

Implications for emerging ocean NETs governance

Knowledge

system/discourse

Economic

\begin{abstract}
ocean NETs approaches.
\end{abstract}
Cultural

Governance is needed to preserve the cultural significance of the (natural) ocean

\section{Object (what)}

Ocean NETs approaches with trans-boundary effects. Scale of effects defining criterion

ocean-based interventions would have trans-boundary effects (positive and negative), thereby contravening national

jurisdictions and raising the risk of conflict

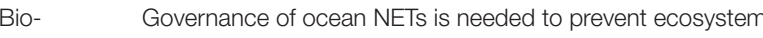
geochemical damage, maintain marine biogeochemical systems, protect biological diversity

Ocean NETs approaches (regardless of scale) that have biogeochemical ecosystem effects. Environmental effects defining criterion

Cost-effective NETs approaches to be enabled,

non-cost-effective to be restricted.

Cost-effectiveness as defining criterion

NETs approaches that are non-natural or invasive,

that change the character of cultural (human)

interactions with the ocean, alter human

understandings of the natural

Social acceptability within a given context as

defining criterion

\section{Actors (who)}

\section{Modes and instruments (how)}

Legal experts, states, and international maritime Global/international, top-down International laws, guidelines

bodies (LC/LP, UNCLOS,

IOC, CBD)

\section{Marine biology,}

biogeochemical and

Global to local, top-down, monitoring, enforcing

biodiversity experts, NGOs, compliance with regulations

international maritime

bodies (LC/LP, UNCLOS,

$\mathrm{IOC}, \mathrm{CBD})$

Economic experts,

assessment bodies,

industrial, and commercia

actors

Global to local,

coordination/competition in flat

hierarchies to allow the most

cost-effective solutions

to emerge

Cultural anthropology

experts, local communities, participatory engagement NGOs, indigenous groups

a LC/LP, London Convention/London Protocol on The Prevention of Marine Pollution by Dumping of Wastes and Other Matter; UNCLOS, United Nations Convention for the Law of the Sea; IOC, Intergovernmental Oceanographic Commission of UNESCO; CBD, Convention on Biological Diversity. 
NETs and climate engineering more broadly. These literatures have demonstrated that ocean interventions raise complex questions surrounding governance, which are not always within the scope of scientific/expert forms of knowledge. Discussions on the governance of ocean interventions seem likely to implicate an even wider range of discourses and types of knowledge than land-based NETs. Indeed, discussion over the emergent UNCLOS Global Ocean Treaty, which aims to protect biodiversity on the High Seas, reveals that different nations and people have very different understandings of the ocean, including whether it represents the "common heritage of mankind" (Silver et al., 2020). Similar differences concerning fundamental definitions and values were important in ocean iron fertilization controversies (Gannon and Hulme, 2018). Researchers working on ocean NETs would benefit from understanding how these diverse knowledge types may affect upstream governance of their work. They also raise tricky questions for public attitudes, because of the way in which the ocean is perceived as fragile, vital to human life, emotionally valuable, interconnected, and challenging to experiment on in an accurate and controllable manner. Evidence therefore suggests that the majority of ocean NETs will face a greater public acceptability challenge than terrestrial NETs. People will need to be assured that controlled, reversible and reliable testing can be carried out, and attempting to "communicate around" uncertainty or downplay risks is likely to backfire. That said, ocean NETs are highly diverse, and empirical research may reveal that some proposals encounter lower risk perceptions; our treatment of ocean NETs as a broad category in this short piece should not be taken to imply homogeneity. For example, some ocean NETs such as coastal habitat restoration do not claim to have trans-boundary effects, which means that they may not encounter the same governance challenges as NETs in the High Seas, and may not encounter public concerns about messing with nature. However, further research is needed, with no substitute for bespoke empirical testing. The remainder of this section sets out principles which can be used to guide responsible research and innovation in this field.

This paper has explored diverse bodies of literature on multiple social science topics, yet they all point toward the need for broad, participatory frameworks to address these issues. Engaging with a broader spectrum of actors early on can help to facilitate the development of techniques in an effective and ethical manner (Fiorino, 1990). The early stage of ocean NETs research creates unique opportunities in this regard, because the technologies and their governance are not yet "locked in." Therefore, participatory approaches could enable flexibility for establishing options for ocean NETs, including how the problems are defined, what methods are used, what criteria are selected, whose perspectives are included, and how uncertainties are conveyed (Stirling, 2007). However, previous participatory approaches have revealed challenges and constraints which will need addressing in social science research on ocean NETs. Firstly, there is the need to ensure that broader perspectives are actually integrated into the technology development, rather than as an add-on, an afterthought, or a legitimization exercise (Markusson et al., 2020). Secondly, more research is needed into frameworks for responsible incentivization, including policy mechanisms which might be able to incentivize ocean NETs even in absence of a high carbon price (Cox and Edwards, 2019). Such work needs to be better integrated into public attitudes research, that we might better understand the two-way relationship between public attitudes and policy: the ways in which publics generate the policy mandate for the incentivization of technologies, and the ways in which public attitudes depend on the policy frameworks used. Ocean NETs also raise challenges around the equitable distribution of risks and benefits, particularly for communities who are highly dependent on the ocean for their basic needs, and research is needed into the perspectives of coastal communities which may be among the most vulnerable to ocean impacts. Addressing the imbalance which currently exists in social science research on NETs, wherein the majority of information comes from Western and OECD samples, should be a priority.

There remains a lot to be done to explore the link between discursively (re)produced knowledge and ocean NETs governance development. Discursive mapping of the wider ocean NETs debate would help to identify which types of knowledge are being privileged or neglected, and what implications this may have for the emergence of ocean NETs governance. Furthermore, bringing these discourses to light may help to anticipate tensions between knowledge systems, mitigate potential conflict by integrating different knowledge types in NETs decisionmaking, and design deliberative processes to further "open up" discursive diversity in ocean NETs governance. The conceptual categorizations outlined in Table 1 could provide the basis for several (complementary or competing) ocean NETs governance narratives for use in deliberative engagement. Discourse has been called "the source code with which contested futures are written" (Boettcher, 2019), and the idea of ocean NETs is likely to set the stage for a whole new range of contested futures. Further elucidating the shaping role of discourses underpinning the NETs debate is therefore key to anticipating and critically reflecting upon the emergence of ocean NETs governance.

Societal uncertainties are likely to play a key role in the emergence of NETs as a potential climate strategy. We therefore make a call for future research to "cast a wider net" on ocean NETs by taking societal and political "demand-side" dynamics seriously.

\section{DATA AVAILABILITY STATEMENT}

The original contributions presented in the study are included in the article/supplementary material, further inquiries can be directed to the corresponding author/s.

\section{AUTHOR CONTRIBUTIONS}

All authors contributed equally to the production of this paper.

\section{FUNDING}

EC and ES were funded by the Leverhulme Trust under project research grant RC-2015-029. 


\section{REFERENCES}

Amelung, D., and Funke, J. (2015). Laypeople's risky decisions in the climate change context: climate engineering as a risk-defusing strategy? Hum. Ecol. Risk Assess. Int. J. 21, 533-559. doi: 10.1080/10807039.2014.932203

Ankamah-Yeboah, I., Xuan, B. B., Hynes, S., and Armstrong, C. W. (2020). Public perceptions of deep-sea environment: evidence from scotland and norway. Front. Mar. Sci. 7:137. doi: 10.3389/fmars.2020.00137

Asayama, S., Sugiyama, M., and Ishii, A. (2017). Ambivalent climate of opinions: Tensions and dilemmas in understanding geoengineering experimentation. Geoforum 80, 82-92. doi: 10.1016/j.geoforum.2017.01.012

Bellamy, R. (2018). Incentivize negative emissions responsibly. Nat. Energy 3, 532-534. doi: 10.1038/s41560-0180156-6

Bellamy, R., Chilvers, J., Vaughan, N. E., and Lenton, T. M. (2012). A review of climate geoengineering appraisals. Wiley Interdiscip. Rev. Clim. Change 3, 597-615. doi: 10.1002/wcc.197

Bellamy, R., Chilvers, J., Vaughan, N. E., and Lenton, T. M. (2013). 'Opening up' geoengineering appraisal: multi-criteria mapping of options for tackling climate change. Glob. Environ. Change 23, 926-937. doi: 10.1016/j.gloenvcha.2013.07.011

Bellamy, R., Lezaun, J., and Palmer, J. (2017). Public perceptions of geoengineering research governance: an experimental deliberative approach. Glob. Environ. Change 45, 194-202. doi: 10.1016/j.gloenvcha.2017.06.004

Bellamy, R., Lezaun, J., and Palmer, J. (2019). Perceptions of bioenergy with carbon capture and storage in different policy scenarios. Nat. Commun. 10:743. doi: 10.1038/s41467-019-08592-5

Biermann, F., and Möller, I. (2019). Rich man's solution? Climate engineering discourses and the marginalization of the Global South. Int. Environ. Agreem. Polit. Law Econ. 19, 151-167. doi: 10.1007/s10784-019-09431-0

Boettcher, M. (2019). Cracking the code: how discursive structures shape climate engineering research governance. Environ. Polit. 29, 890-916. doi: $10.1080 / 09644016.2019 .1670987$

Boettcher, M. (2020). Coming to GRIPs with NETs discourse: implications of discursive structures for emerging governance of negative emissions technologies in the UK. Front. Clim. 2:595685. doi: 10.3389/fclim.2020.595685

Brent, K., Burns, W., and McGee, J. (2019). Governance of Marine Geoengineering (Special Report). Waterloo, ON: Centre for International Governance Innovation.

Buck, H. J. (2014). "Village science meets global discourse : The Haida Salmon Restoration Corporation's ocean iron fertilisation experiment," in Geoengineering Our Climate? Ethics, Politics, and Governance, eds J. J. Blackstock and S. Low (Abingdon: Routledge), 107-112. doi: $10.4324 / 9780203485262-19$

Butler, C., Parkhill, K., and Pidgeon, N. F. (2013). Deliberating Energy System Transitions in the UK, Transforming the UK Energy System: Public Values, Attitudes and Acceptability. London: UK Energy Research Centre.

Capstick, S. B., Pidgeon, N. F., Corner, A. J., Spence, E. M., and Pearson, P. N. (2016). Public understanding in Great Britain of ocean acidification. Nat. Clim. Change 6, 763-767. doi: 10.1038/nclimate3005

Carr, W. A., and Yung, L. (2018). Perceptions of climate engineering in the South Pacific, Sub-Saharan Africa, and North American Arctic. Clim. Change 147, 119-132. doi: 10.1007/s10584-018-2138-x

Cooke, S. L., and Kim, S. C. (2019). Exploring the "evil twin of global warming": public understanding of ocean acidification in the United States. Sci. Commun. 41, 66-89. doi: $10.1177 / 1075547018821434$

Corner, A., Parkhill, K., Pidgeon, N., and Vaughan, N. E. (2013). Messing with nature? Exploring public perceptions of geoengineering in the UK. Glob. Environ. Change 23, 938-947. doi: 10.1016/j.gloenvcha.2013.06.002

Cox, E., and Edwards, N. R. (2019). Beyond carbon pricing: policy levers for negative emissions technologies. Clim. Policy 19, 1144-1156. doi: 10.1080/14693062.2019.1634509

Cox, E., Pidgeon, N., Spence, E., and Thomas, G. (2018). Blurred lines: the ethics and policy of greenhouse Gas Removal at scale. Front. Environ. Sci. 6:38. doi: $10.3389 /$ fenvs. 2018.00038

Cox, E., Spence, E., and Pidgeon, N. (2020a). Incumbency, trust and the monsanto effect: stakeholder discourses on greenhouse gas removal. Environ. Values 29, 197-220. doi: 10.3197/096327119X15678473650947
Cox, E., Spence, E., and Pidgeon, N. (2020b). Public perceptions of Carbon Dioxide Removal in the US and UK. Nat. Clim. Change 10, 744-749. doi: 10.1038/s41558-020-0823-z

Cummings, C., Lin, S., and Trump, B. (2017). Public perceptions of climate geoengineering: a systematic review of the literature. Clim. Res. 73, 247-264. doi: $10.3354 / \mathrm{cr} 01475$

Dwyer, J., and Bidwell, D. (2019). Chains of trust: Energy justice, public engagement, and the first offshore wind farm in the United States. Energy Res. Soc. Sci. 47, 166-176. doi: 10.1016/j.erss.2018.08.019

Fiorino, D. J. (1990). Citizen participation and environmental risk: a survey of institutional mechanisms. Sci. Technol. Hum. Val. 15, 226-243. doi: $10.1177 / 016224399001500204$

Fischhoff, B., Slovic, P., Lichtenstein, S., Read, S., and Combs, B. (1978). How safe is safe enough? A psychometric study of attitudes towards technological risks and benefits. Policy Sci. 9, 127-152. doi: 10.1007/BF00143739

Fuentes-George, K. (2017). Consensus, certainty, and catastrophe: discourse, governance, and ocean iron fertilization. Glob. Environ. Polit. 17, 125-143. doi: 10.1162/GLEP_a_00404

Gannon, K. E., and Hulme, M. (2018). Geoengineering at the "Edge of the World": exploring perceptions of ocean fertilisation through the Haida Salmon Restoration Corporation. Geo Geogr. Environ. 5:e00054. doi: 10.1002/geo2.54

Gattuso, J.-P., Magnan, A. K., Bopp, L., Cheung, W. W. L., Duarte, C. M., Hinkel, J., et al. (2018). Ocean solutions to address climate change and its effects on marine ecosystems. Front. Mar. Sci. 5:337. doi: 10.3389/fmars.2018.00337

GESAMP (2019). High Level Review of a Wide Range of Proposed Marine Geoengineering Techniques (Report of GESAMP Working Group 41 No. 98). London: International Maritime Organisation.

Gordon, C. (1991). "Governmental rationality: an introduction," in The Foucault Effect: Studies in Governmentality, eds G. Burchell, C. Gordon, and P. Miller (Chicago, IL: University of Chicago Press), 1-52.

Gough, C., and Mander, S. (2019). Beyond social acceptability: applying lessons from CCS social science to support deployment of BECCS. Curr. Sustain. Energy Rep. 6, 116-123. doi: 10.1007/s40518-019-0 0137-0

Gupta, A., and Möller, I. (2019). De facto governance: how authoritative assessments construct climate engineering as an object of governance. Environ. Polit. 28, 480-501. doi: 10.1080/09644016.2018.14 52373

Harnisch, S., Uther, S., and Boettcher, M. (2015). From "go slow" to "gung ho"? Climate engineering discourses in the UK, the US, and Germany. Glob. Environ. Polit. 15, 57-78. doi: 10.1162/GLEP_a_00298

Hawkins, J. P., O'Leary, B. C., Bassett, N., Peters, H., Rakowski, S., Reeve, G., et al. (2016). Public awareness and attitudes towards marine protection in the United Kingdom. Mar. Pollut. Bull. 111, 231-236. doi: 10.1016/j.marpolbul.2016.07.003

Horton, Z. (2017). Going rogue or becoming salmon? Geoengineering narratives in Haida Gwaii. Cult. Crit. 97, 128-166. doi: 10.5749/culturalcritique.97.2017.0128

Hulme, M. (2010). Problems with making and governing global kinds of knowledge. Glob. Environ. Change 20, 558-564. doi: 10.1016/j.gloenvcha.2010.07.005

IMO (2020). Convention on the Prevention of Marine Pollution by Dumping of Wastes and Other Matter [WWW Document]. Available online at: http:// www.imo.org/en/OurWork/Environment/LCLP/Pages/default.aspx (accessed October 15, 2020).

IOC (2010). Ocean Fertilization: A Scientific Summary for Policy Makers (No. IOC/BRO/2010/2). Paris: Intergovernmental Oceanographic Commission.

Ipsos Mori (2010). Experiment Earth? Report on a Public Dialogue on Geoengineering. Swindon: Natural Environment Research Council.

Jobin, M., and Siegrist, M. (2020). Support for the deployment of climate engineering: a comparison of ten different technologies. Risk Anal. 40, 1058-1078. doi: 10.1111/risa.13462

Keller, D. (2018). "Marine Climate-engineering," in Handbook on Marine Environmental Protection: Science, Impacts and Sustainable Management, eds M. Salomon and T. Markus (Cham: Springer International Publishing), 261276. doi: 10.1007/978-3-319-60156-4

Keller, R. (2011). The sociology of knowledge approach to discourse (SKAD). Hum. Stud. 34, 43-65. doi: 10.1007/s10746-011-9175-z 
Leipold, S., Feindt, P. H., Winkel, G., and Keller, R. (2019). Discourse analysis of environmental policy revisited: traditions, trends, perspectives. J. Environ. Policy Plan. 21, 445-463. doi: 10.1080/1523908X.2019.1660462

Lockwood, T. (2017). Public Outreach Approaches for Carbon Capture and Storage Projects. London: IEA Clean Coal Centre.

Lomax, G., Workman, M., Lenton, T., and Shah, N. (2015). Reframing the policy approach to greenhouse gas removal technologies. Energy Policy 78, 125-136. doi: 10.1016/j.enpol.2014.10.002

Low, S., and Boettcher, M. (2020). Delaying decarbonization: climate governmentalities and sociotechnical strategies from Copenhagen to Paris. Earth Syst. Gov. 5:100073. doi: 10.1016/j.esg.2020.100073

Low, S., and Schäfer, S. (2020). Is bio-energy carbon capture and storage (BECCS) feasible? The contested authority of integrated assessment modeling. Energy Res. Soc. Sci. 60:101326. doi: 10.1016/j.erss.2019.101326

Luisetti, T., Turner, R. K., Andrews, J. E., Jickells, T. D., Kröger, S., Diesing, M., et al. (2019). Quantifying and valuing carbon flows and stores in coastal and shelf ecosystems in the UK. Ecosyst. Serv. 35, 67-76. doi: 10.1016/j.ecoser.2018.10.013

Mabon, L., and Shackley, S. (2015). Meeting the targets or re-imagining society? An empirical study into the ethical landscape of carbon dioxide capture and storage in Scotland. Environ. Val. 24, 465-482. doi: 10.3197/096327115X14345368709907

Mabon, L., Shackley, S., and Bower-Bir, N. (2014). Perceptions of sub-seabed carbon dioxide storage in Scotland and implications for policy: a qualitative study. Mar. Policy Compl. 45, 9-15. doi: 10.1016/j.marpol.2013.11.011

Macnaghten, P., Davies, S. R., and Kearnes, M. (2015). Understanding public responses to emerging technologies: a narrative approach. J. Environ. Policy Plan 21, 504-518. doi: 10.1080/1523908X.2015.1053110

Markusson, N., Balta-Ozkan, N., Chilvers, J., Healey, P., Reiner, D., and McLaren, D. (2020). Social science sequestered. Front. Clim. 2:2. doi: $10.3389 /$ fclim.2020.00002

Matzner, N., and Barben, D. (2018). "Verantwortungsvoll das Klima manipulieren? Unsicherheit und Verantwortung im Diskurs um Climate Engineering," in Unsicherheit Als Herausforderung Für Die Wissenschaft, eds N. Janich and L. Rhein (Berlin: Peter Lang), 143-178.

Matzner, N., and Barben, D. (2020). Climate engineering as a communication challenge: contested notions of responsibility across expert arenas of science and policy. Sci. Commun. 354, 182-183. doi: 10.1177/1075547019899408

McDonald, J., McGee, J., Brent, K., and Burns, W. (2019). Governing geoengineering research for the Great Barrier Reef. Clim. Policy 19, 801-811. doi: 10.1080/14693062.2019.1592742

McLaren, D. P. (2018). Whose climate and whose ethics? Conceptions of justice in solar geoengineering modelling. Energy Res. Soc. Sci. 44, 209-221. doi: 10.1016/j.erss.2018.05.021

McMahan, E. A., and Estes, D. (2015). The effect of contact with natural environments on positive and negative affect: a meta-analysis. J. Posit. Psychol. 10, 507-519. doi: 10.1080/17439760.2014.994224

Möller, I. (2020). Political perspectives on geoengineering: navigating problem definition and institutional fit. Glob. Environ. Polit. 20, 57-82. doi: 10.1162/glep_a_00547

Myatt, L. B., Scrimshaw, M. D., and Lester, J. N. (2003). Public perceptions and attitudes towards an established managed realignment scheme: Orplands, Essex, UK. J. Environ. Manage. 68, 173-181. doi: 10.1016/S0301-4797(03)00065-3

National Academies of Sciences, Engineering and Medicine (2019). Negative Emissions Technologies and Reliable Sequestration: A Research Agenda. Washington, DC: National Academies Press. doi: 10.17226/ 25259

Nemet, G. F., Callaghan, M. W., Creutzig, F., Fuss, S., Hartmann, J., Hilaire, J., et al. (2018). Negative emissions-Part 3: innovation and upscaling. Environ. Res. Lett. 13:063003. doi: 10.1088/1748-9326/aabff4
Owen, R., Bessant, J. R., and Heintz, M. (2013). Responsible Innovation: Managing the Responsible Emergence of Science and Innovation in Society. Chichester: John Wiley and Sons.

Palmgren, C. R., Morgan, M. G., De Bruin, W. B., and Keith, D. W. (2004). Initial public perceptions of deep geological and oceanic disposal of carbon dioxide. Environ. Sci. Technol. 38, 6441-6450. doi: 10.1021/es040400c

Pidgeon, N., Parkhill, K., Corner, A., and Vaughan, N. (2013). Deliberating stratospheric aerosols for climate geoengineering and the SPICE project. Nat. Clim. Change 3, 451-457. doi: 10.1038/nclimate1807

Potts, T., Pita, C., O'Higgins, T., and Mee, L. D. (2016). Who cares? European attitudes towards marine and coastal environments. Mar. Policy 72, 59-66. doi: 10.1016/j.marpol.2016.06.012

Royal Society and Royal Academy of Engineering (2018). Greenhouse Gas Removal. London: Royal Society and Royal Academy of Engineering.

Silver, J., Acton, L., Campbell, L., and Gray, N. (2020). How a Global Ocean Treaty Could Protect Biodiversity in the High Seas. The Conversation. Available online at: http://theconversation.com/how-a-global-ocean-treatycould-protect-biodiversity-in-the-high-seas-139552 (accessed October 15, 2020).

Slovic, P. (1987). Perception of risk. Science 236, 280-285. doi: $10.1126 /$ science. 3563507

Spence, E., Pidgeon, N., and Pearson, P. (2018). UK public perceptions of ocean acidification - the importance of place and environmental identity. Mar. Policy Mar. 97, 287-293. doi: 10.1016/j.marpol.2018.04.006

Srivastava, S., and Mehta, L. (2017). The Social Life of Mangroves - Resource Complexes and Contestations on the Industrial Coastline of Kutch, India (STEPS Centre Working Paper). Falmer: Institute for Development Studies, University of Sussex.

Stirling, A. (2007). Risk, precaution and science: towards a more constructive policy debate. Talking point on the precautionary principle. EMBO Rep. 8, 309-315. doi: 10.1038/sj.embor.7400953

Strong, A., Cullen, J., and Chisholm, S. (2015). Ocean fertilization: science, policy, and commerce. Oceanography 22, 236-261. doi: 10.5670/oceanog.2 009.83

Waller, L., Rayner, T., Chilvers, J., Gough, C. A., Lorenzoni, I., Jordan, A., et al. (2020). Contested framings of greenhouse gas removal and its feasibility: social and political dimensions. WIREs Clim. Change 11:e649. doi: 10.1002/wcc.649

Wibeck, V., Hansson, A., Anshelm, J., Asayama, S., Dilling, L., Feetham, P. M., et al. (2017). Making sense of climate engineering: a focus group study of lay publics in four countries. Clim. Change 145, 1-14. doi: 10.1007/s10584-017-2067-0

Williams, L., Macnaghten, P., Davies, R., and Curtis, S. (2017). Framing 'fracking': exploring public perceptions of hydraulic fracturing in the United Kingdom. Public Underst. Sci. 26, 89-104. doi: 10.1177/0963662515595159

Winickoff, D. E., Flegal, J. A., and Asrat, A. (2015). Engaging the Global South on climate engineering research. Nat. Clim. Change 5, 627-634. doi: $10.1038 /$ nclimate 2632

Wolske, K. S., Raimi, K. T., Campbell-Arvai, V., and Hart, P. S. (2019). Public support for carbon dioxide removal strategies: the role of tampering with nature perceptions. Clim. Change 152, 345-361. doi: 10.1007/s10584-019-02375-z

Conflict of Interest: The authors declare that the research was conducted in the absence of any commercial or financial relationships that could be construed as a potential conflict of interest.

Copyright $\odot 2021$ Cox, Boettcher, Spence and Bellamy. This is an open-access article distributed under the terms of the Creative Commons Attribution License (CC BY). The use, distribution or reproduction in other forums is permitted, provided the original author(s) and the copyright owner(s) are credited and that the original publication in this journal is cited, in accordance with accepted academic practice. No use, distribution or reproduction is permitted which does not comply with these terms. 